\title{
Cultural Safety for Mi'kmaw Students and Staff at Cape Breton University
}

\author{
Heather Schmidt, Cape Breton University
}

\begin{abstract}
Cultural safety reflects the extent to which an individual feels that their culture is respected, accepted and understood by the larger society in which they live. The concept was originally developed in the context of Indigenous Peoples, but it could also easily be applied to members of other minority groups whose voices are underrepresented in mainstream society (e.g., the LGBT community, the differently-abled, other ethnic minorities). In this paper, I discuss my ongoing efforts to assess and measure cultural safety in Mi'kmaw First Nation students, staff and faculty at a small university in northern Nova Scotia. To maximize the chances of Indigenous students graduating and achieving to their full-potential within post-secondary institutions, we need to stop and ask whether they feel a sense of belonging, connection and cultural safety on-campus. If the answer is 'No' or 'Only in the Aboriginal student centre', then we need to collaborate with Indigenous students to design and implement interventions. These may involve altering both the physical campus and the way in which non-Native individuals on-campus think about and relate to Indigenous culture and individuals.
\end{abstract}

Cultural safety is a concept that was developed in the mid-1980s by a Maori nursing graduate student in New Zealand who saw a need for nurses to move beyond the concept of "cultural sensitivity" (Ramsden \& Spoonley, 1994). Cultural sensitivity training tends to focus on privileged members of society: teaching them to be more tolerant of minority groups, so that they are less likely to offend others when interacting. In this approach, training is delivered and the privileged individuals complete a test before and after the training to evaluate whether there was a positive change in their level of sensitivity. There are several problems with this approach, however. For one, it is considered socially-undesirable in our modern society to be discriminatory. This doesn't mean that discrimination has been eliminated, but rather that it has become more subtle than the 'blatant racism' of the KKK, for example. Modern discrimination often comes masked in the form of statements like "I'm not a racist of course, but I don't know about those people" or "My friend is gay and so I'm not homophobic, but it bugs me when..." Social-desirability suggests that people may select the "politically correct" responses on measures of cultural sensitivity (i.e., not responding honestly) because they want to think of themselves as a "good person" and they want other people to think well of them also.

I attended a presentation at a community psychology conference in 2011 at which the researchers were describing a puzzling result of their new cultural-sensitivity training program and measure: In their study, a group of working professionals had completed the test and then listened to a presentation by a gay, African-American woman in a wheelchair who passionately talked about what she wished people better understood about her, and common sources of discrimination and difficulties that she encountered. Then the cultural sensitivity test was completed again. While the participants noted that they had found the experience eye-opening and enlightening, unfortunately their test scores actually implied that their cultural sensitivity had 
decreased! What was going on? On one hand, some might argue that "old habits die hard" and that it is not easy to change attitudes. On the other hand, some might argue that the individuals became more self-aware while listening to the speaker (i.e., recognizing their own thoughts and actions in the speaker's stories), and so perhaps they answered the measure of cultural sensitivity more honestly the second time around. It is hard to know one way or the other.

Ramsden and Spoonley (1994) suggested that an alternative response to this problem is to prioritize the perspectives of the minority group(s) in question (the Indigenous Maori in their research) and ask them to determine whether an acceptable level of "cultural safety" has been achieved: Are the training programs resulting in noticeable changes in the attitudes and behaviours of "trainees"? Are these changes perceived as any improvement by Indigenous peoples? To what extent do they feel that their culture and people are being treated with more respect and understanding by non-Natives? Rather than only involving privileged members of society in the assessment (i.e., researchers and the trainees), the cultural safety approach acknowledges and corrects for power imbalances, institutional discrimination and colonization and responds by giving power and voice to Indigenous peoples.

The concept of cultural safety has continued developing in the Nursing and health services field (although there has been some reported backlash and resistance). In spite of a call by Canada's National Aboriginal Health Organization (Brascoupe \& Waters, 2009) to expand research on cultural safety to other fields (such as the legal system, and the education system, including universities), very few researchers outside of nursing and health-services have taken up the challenge. Why is cultural safely so important in schools, such as post-secondary institutions?

Using somewhat similar concepts, Drs. Martin Brokenleg (Lakota-Sioux) and Steve Van Bockern (2003) emphasize the vital importance of students feeling a sense of Belonging / Connection in their educational environment. Figures 1 and 2 contrast a healthy school climate (or "Circle of Courage") with an unhealthy school climate or "Broken Circle".
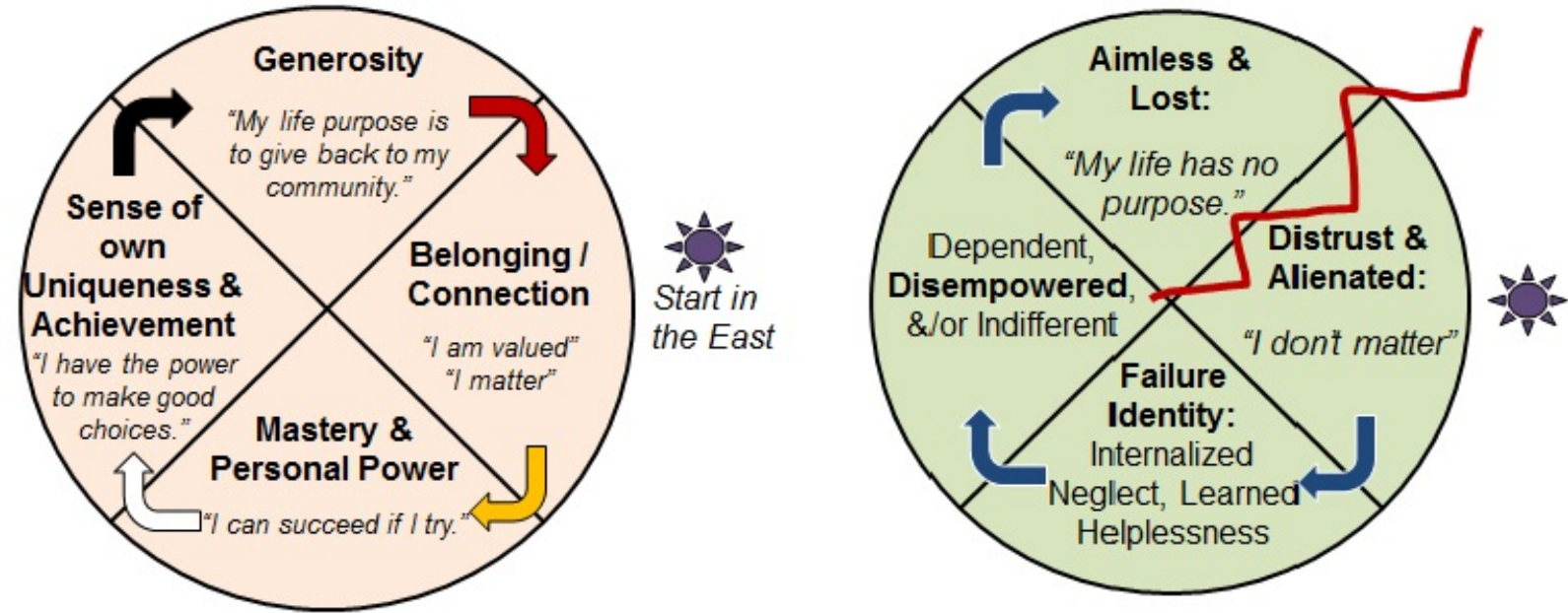

Figures 1 \& 2 A healthy 'Circle of Courage' and a 'Broken Circle'

In the healthy model, instructors know students' names, notice if they are absent, and are genuinely invested in students' wellbeing. Students also make friends and join clubs. All of this shows the students that they are important and connected to other people. With this foundation in place, the student gains the confidence to try difficult tasks and is encouraged to persist until success is achieved, knowing that they can reach out for support as needed. Having acquired a sense one's own Personal Power, the student is then ready for increased responsibility. Still 
within this supportive environment, the student is given tasks to help them discover their unique talents. They feel proud and good about themselves as a result. Lastly, Brokenleg and Van Bockern (2003) state that a healthy school provides its students with opportunities to help each other and to give back to the system that helped them to succeed and mature. Students graduate with a clear sense of purpose and social-responsibility, ready to nurture the next generation via Belonging/Connection. Healthy individuals emerge from within a healthy social environment. As seen in Figure 2, however, when students feel misunderstood and alienated at school, this leads to a pattern of underachievement, learned helplessness, and aimlessness: students may drop out because they feel like “I don’t belong”, “I don't matter” and “My life has no purpose”.

In 2011, honours student Samantha Iannetti and I conducted a Needs Assessment study at Cape Breton University to determine how well our educational institution was meeting the needs of Mi'kmaw students and staff. Did they feel a sense of belonging and connection? Did they feel culturally-safe on our campus?

\section{Methods}

\section{Participants}

We conducted a series of semi-structured qualitative interviews with CBU's Mi'kmaw college staff and faculty members (called “Unama'ki College”), and similar focus groups with Mi'kmaw students. Seven (7) staff/faculty participated, as did eleven (11) students. Among the staff/faculty, 3 were Mi'kmaw and 4 were non-Native. We recruited professors from sciences, humanities, and social sciences; Some taught on-campus, while others taught intro-level university courses in the local First Nation communities. The students represented 7 different Mi'kmaw First Nations. Their ages ranged from 18-44 (with an average of 25). There were 8 women and 3 men, and there was diversity in terms of the degrees they were completing (i.e., Bachelors of Arts, Science, Nursing, and Community Studies were represented).

\section{Procedure}

The interviews and focus groups consisted of a core set of questions: (1) What comes to mind when you think about the experiences of Mi'kmaw students at CBU? (2) What challenges do Mi'kmaw students face in trying to complete their education? and (3) What services/supports are currently in place for Mi'kmaw students? How well do they meet the needs of students? What improvements can be made?

Whenever possible, we provided these questions to the participants in advance, in order to allow them sufficient time to think about the issues. This generally worked well with staff/faculty, who we recruited using a combination of purposive sampling and snowball sampling. However, we wound up recruiting most students by dropping into the Mi'kmaw Student Centre over the lunch-hour, quickly explaining our study, and asking who was willing to participate in a focus group right at that time. We provided lunch but also clarified that nobody was obligated to stay and that they were free to take a sandwich and leave. Although initially several students said that they could not stay for the full group, they generally became quite immersed in the discussion and stayed until the end. All sessions were digitally-recorded, transcribed, and then analyzed using Grounded Theory techniques to pull out emerging themes and patterns. 


\section{Results}

One theme involved the essential role played by the Unama'ki College in fostering a sense of belonging and support for Mi'kmaw students at CBU. On the other hand, another key theme emerged as a Lack of Connectedness between Mi'kmaw students/staff/faculty and the university more broadly. Two students stated:

"I’d probably be alone eating in the bathroom without the Mi'kmaw College."

“If there was no Mi'kmaw College, most of these people wouldn't even come to school."

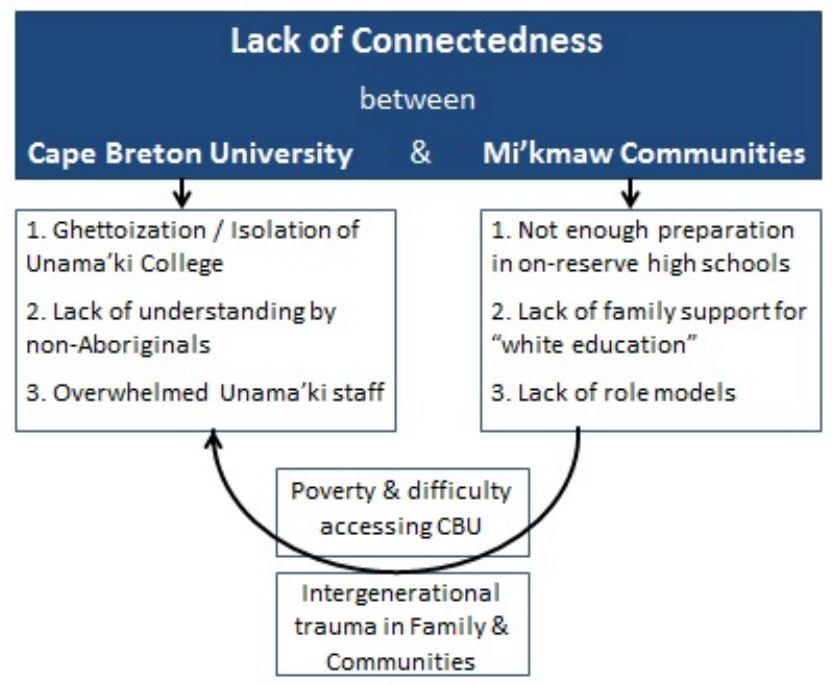

Figure 3 Theme reflecting Lack of Connectedness

As seen in Figure 3, staff/faculty spoke about feeling overwhelmed because they often acted as counsellors to distressed Indigenous students, even though they often lacked the training, resources, and time. Furthermore, students, staff, and faculty all reported that they felt like the Mi’kmaw College was isolated and hidden on-campus, making them feel 'ghettoized':

I feel like we're shoved in a corner. We're hidden. You have to go so far in the back of the college to find where we are. (Student)

They have that beautiful display of all that Native stuff but it's hidden [in the Mi'kmaw college]. Why can't that be out in the open? (Student)

Can we start to see some Mi'kmaw art in the hallways? Some indication of other aspects of Aboriginal people throughout the university and not just, once again, to that one physical location called the Unama'ki College? What kind of message does it send when we ghettoize our Indigenous cultures to one physical spot? (Faculty) 
On a more positive note, the participants had an abundance of ideas about how to improve this situation and were enthusiastic to share their ideas. Figure 4 depicts some of the solutions they discussed.

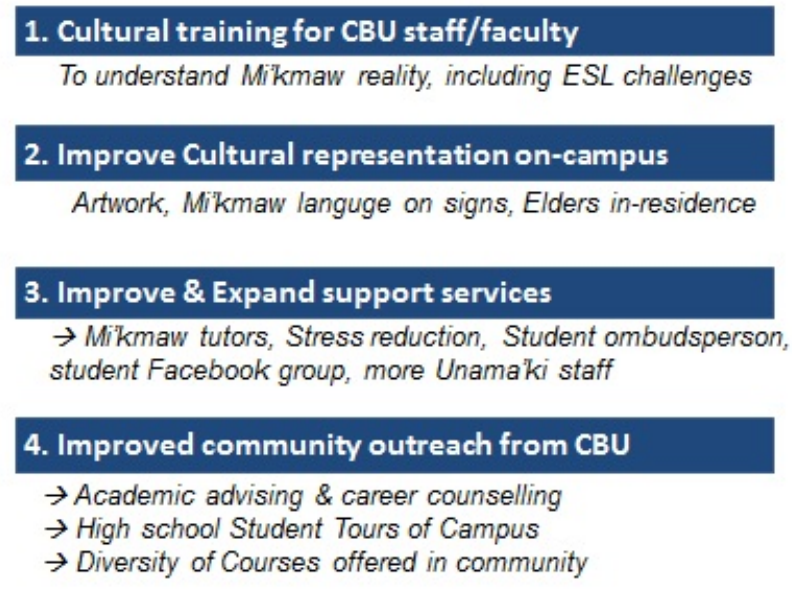

Figure 4 Solutions to improving Connectedness

The first suggestion is for non-Native staff, faculty and even students at CBU to engage in some form of Cultural Training, to help them understand Mi'kmaw culture, history and current reality. As noted in Figure 4, the participants stated that very few people at CBU are aware that Mi'kmaw (not English) is the first language of a significant number of Mi'kmaw students. In addition to making communication a challenge (particularly between students and professors), the participants also stated that it would mean a great deal to them if signs around campus were translated into the Mi'kmaw language, in the same way that CBU posts signage in other languages for the international students. Having their language needs better understood would help to make Mi'kmaw students, staff and faculty feel more respected, acknowledged, and like they belong within the university community.

\section{Further Actions}

Since sharing our findings with the CBU administration, improvements have been made to signage and support services on-campus. To further improve cultural safety for the Mi'kmaw population at CBU, we still need to design and deliver the above-mentioned cultural training. In addition to informing people about language issues, I believe it would also be helpful to correct divisive but mistaken beliefs such as "All First Nation students get their education for free at the tax-payers' expense." We also need to explore effective strategies for disseminating these messages. Simply providing information is often not enough to change attitudes and behaviours.

When examining the literature on cultural safety, much of it is qualitative or theoretical in nature. Lacking are quantitative ways of assessing cultural safety across time. With no concrete measures, how will we know if our cultural training was effective? My students and I have developed a quantitative self-report Mi'kmaw Cultural Safety Measure, on which participants can circle a number between 1 and 5 to indicate the extent to which they agree or disagree with a 
series of statements. Sample statements include "My non-Native professors understand the needs of Mi'kmaw students", "I feel comfortable taking classes at CBU in which there are very few other Mi'kmaw students" and "CBU stays connected to Mi'kmaw culture". To maximize the chances of Indigenous students graduating and achieving to their full-potential within postsecondary institutions, we need to stop and ask whether they feel a sense of belonging/connection and cultural safety on-campus. If the answer is 'No' or 'Only in the Aboriginal student centre', then we need to work alongside Indigenous students and staff to change our educational environment for the better.

\section{References}

Brascoupé, S., \& Waters, C. (2009). Cultural safety: Exploring the applicability of the concept of cultural safety to aboriginal health and community wellness. Journal of Aboriginal Health, 5(2), 6-41.

Brokenleg, M., \& Van Bockern, S. (2003). The science of raising courageous kids. Reclaiming Children and Youth, 12(1), 22-26.

Ramsden, I., \& Spoonley, P. (1994). The cultural safety debate in nursing education in Aotearoa. New Zealand Annual Review of Education, 3, 161-174.

\section{Authors' Biography}

Dr. Heather Schmidt is an Assistant Professor of Psychology at Cape Breton University. She specializes in Participatory Action Research and Community Psychology. 